\title{
Contemporary View on Etiopathogenesis of Metabolic Syndrome
}

\author{
Mukhamedova M.G* \\ Tashkent Postgraduate Medical Institute, Tashkent, Uzbekistan \\ ${ }^{*}$ Corresponding Author \\ Mukhamedova M.G \\ Article History \\ Received: 05.07 .2019 \\ Accepted: 24.07 .2019 \\ Published: 30.07 .2019

\begin{abstract}
Metabolic syndrome (MS) is a cluster of several risk factors such as abdominal obesity, hypertension, dyslipidemia, insulin resistance and considered risk for the development of the type 2 diabetes mellitus (T2DM) and cardiovascular disease (CVD). Knowing contemporary aspects of the development of this disease allows understanding underlining mechanisms of the MS. This review summarizes modern concepts of the metabolic syndrome and its etiology, pathogenesis and biochemical mechanisms of the development of the metabolic disease.
\end{abstract}

Keywords: Metabolic syndrome; abdominal obesity; insulin resistance; dyslipidemia; hypertension

\section{INTRODUCTION}

Metabolic syndrome (MS) is a complex of symptoms that includes abdominal obesity, reduced sensitivity of peripheral tissues to insulin, hyperinsulinemia, dyslipidemia, which leads to a violation of all types of metabolism, type 2 diabetes and the development of hypertension [1]. MS is a complex of interrelated and modifiable risk factors for the development of cardiovascular diseases (CVD) and type 2 diabetes mellitus (T2DM) [2]. The main components of MS are disorders of carbohydrate metabolism, abdominal obesity, dyslipidemia and arterial hypertension [3].

According to A.L. Alavi et al. patients with MS and coronary heart disease (CHD), mortality from CVD increases 5 times for women and 2 times for men [4], and myocardial infarction and stroke occur in 3, 5 times more often [5]. From the point of view of public health and clinical practice, the obesity epidemic, the pathogenetic basis of which is insulin resistance (IR), becomes the main socio-economic problem of mankind, for which early diagnosis and timely effective treatment of the main components of MS are extremely important [6].

Currently, the issue of metabolic syndrome is considered one of the main in the medical-social and economic orientation of modern society, leading to a decrease in life expectancy and deterioration of its quality. In the present review reviewed the current views on the problem. The chronology of the study and presentation of the components of the metabolic syndrome was studied. Attention is paid to modern factors affecting the development of pathology, as a rule, these are genetic factors, consumption of large amounts of high-calorie foods, and low physical activity. Genetic risk factors may lie in the constitutional characteristics of the composition of muscle fibers, fat distribution, activity and insulin sensitivity of the main enzymes of carbohydrate and fat metabolism [7]. The formation of MS is determined by a genetic predisposition to several groups of candidate genes. Nutritional disorders that often accompany the metabolic syndrome, among which the most common hyperphagic reaction to stress, compulsive hyperphagia, carbohydrate thirst and premenstrual hyperphagia are analyzed [8]. The theme of "multi-profile" of the mentioned pathology, as an epidemic of the 21st century, its influence on the development of disorders of the internal organs is revealed.

The prevalence of metabolic syndrome is 2 times higher than the prevalence of diabetes, and its growth rates are expected to increase by $50 \%$ over the next 25 years" [9]. This problem does not only cover people over 18 years old. Over the past 10 years, the number of children with signs of metabolic syndrome has increased from 4.2 to $6.4 \%$. Excess body weight occurs in $12-14 \%$ of the minor population of economically developed countries [10]. The initial signs of metabolic disorders are detected already at an early age, and, of course, are more often recorded in a group of children with burdened heredity and overweight. When examining adolescents with obesity that developed before the onset of puberty, a high prevalence of hyperinsulinemia and arterial hypertension

Copyright @ 2019: This is an open-access article distributed under the terms of the Creative Commons Attribution license which permits unrestricted use, distribution, and reproduction in any medium for non commercial use (NonCommercial, or CC-BY-NC) provided the original author and source are credited. 
(AH) was noted [11]. Over the age of 18 years, an increase in body weight per kg increases the risk of developing hypertension by $5 \%$, and an increase of $8.0-10.9 \mathrm{~kg}$ increases the risk of cardiovascular diseases by 1.6 times [12].

MS is associated with subclinical damage to vital organs. This is manifested in the reduction of renal filtration function, microalbuminuria, and increase in arterial stiffness, left ventricular myocardial hypertrophy, diastolic dysfunction, increase in the size of the LV cavity, carotid wall thickening, and many of these disorders occur regardless of the presence of hypertension [13]. In Uzbekistan, in patients with android type of obesity, hypertensive disease occurred in $73.3 \%$, CAD in $57.3 \%$, T2DM in $64 \%$, and hypercholesterolemia in $60 \%$ of those examined. In the group of patients with IHD, obesity was found in $62 \%, \mathrm{HB}$ in $58 \%$, hypercholesterolemia in $54 \%$, and type 2 diabetes in $32 \%$ of patients. Among patients with type 2 diabetes, obesity develops in $80 \%$ of patients, hypertension in $68 \%$, hypercholesterolemia in $62 \%$, and coronary artery disease in $65 \%$ of patients [14].

\section{Pathogenetic mechanisms of development of MS}

The founder of the modern concept of MS is an American scientist Gerald Riven (Jerald Reaven), who proposed in 1988 an elegant pathophysiological model for the development of MS, in which the IR phenomenon was called the key factor in the emergence of this condition [15].

The term "insulin resistance" (IR) is understood to mean a decrease in the response of insulin-sensitive tissues to insulin at its sufficient concentration, leading to chronic compensatory hyperinsulinemia. IR is based on various genetic defects responsible for transmitting the signal after insulin combines with its receptor (post-receptor defects) [16]. Normally, autophosphorylation of the receptor occurs with the participation of tyrosine kinase and its subsequent connection with the substrate of the insulin receptor (IRS-1 and -2). IRS molecules activate phosphatidylinositol-3-kinase (PI3K), which stimulates the translocation of glucose transporter GLUT-4 across the cell membrane, which ensures the activation of the metabolic and mitogenic effects of insulin [17]. In patients with IR and type 2 diabetes, the translocation of the glucose transporter is disrupted, and the expression of other genes responsible for the metabolism of glucose and lipids, including mutations of glycogen synthetase genes, hormone-sensitive lipase, tumor necrosis factor (TNF) alpha, uncoupling protein, etc., is disturbed.

It is difficult to find the only root because in the pathogenesis of MS, they are so closely interconnected and interdependent. The basis of MS is insulin resistance (IR) or impaired biological response of body tissues to insulin action, accompanied by a decrease in glucose consumption by tissues. At the same time, the non-oxidative way of consuming this carbohydrate is disturbed to a greater extent - glycogen synthesis, which is a result of the interaction of genetic (defect insulin receptors) and external factors, especially the formation of androgenic obesity and a decrease in blood volume in the capillaries of skeletal muscle as a result of their vasoconstriction, and this affects by increasing the diffusion pathway of glucose to the cells [18]. Target organs of hypertension in people with obesity are affected much earlier, and their changes are much more pronounced than in patients with hypertension without obesity [19]. Scientists have proven that IR and concomitant hyperinsulinemia trigger a number of pathological reactions that are closely associated with endothelial dysfunction and form a vicious circle leading to metabolic diseases [20]. One of the key conditions in the formation of metabolic disorders in MS is the abdominal type of obesity (since an increased amount of visceral fat is combined with IR, hyperinsulinemia (GI), dyslipidemia, and arterial hypertension). In this case, adipose tissue can be considered as a neuroimmune-endocrine organ producing leptin [21]. Leptin, in turn, acts on the centers of hunger and saturation in the hypothalamus, participates in the regulation of energy homeostasis and controls body weight. Researchers believe that obesity causes compensatory resistance of the hypothalamus to the central action of leptin, and, subsequently, through a negative feedback mechanism leads to hyperleptinemia. It is believed that leptin is a link between adipocytes and P-cells of the pancreas and stimulates insulin secretion while reducing sensitivity to the latter. At the same time, leptin level is a signal marker of sufficient accumulation of adipose tissue [22].

Factors affecting the development of MS are well known in modern medicine. This is, first of all, the consumption of large amounts of high-calorie foods and low physical activity. The basis of abdominal obesity is excessive consumption of animal fats containing saturated fatty acids. If the mass of fat consumed exceeds the body's ability to oxidize it, obesity develops and progresses. Saturated fatty acids in excess with food cause structural changes in the phospholipids of cell membranes and disrupt the expression of genes that control the insulin signal in the cell $[6,9]$. In the diet of modern man, there are fewer food products in their natural form, and more processed foods that require a significant amount of oil for cooking, as well as industrial-grade dishes rich in easily digestible carbohydrates. A popular contribution to the development of the disease is the popularization of "fast food" ("fast food"), high-calorie drinks and computerization of leisure. The most important environmental factor is the excessive consumption of animal fats containing saturated fatty acids [23].

About $30-40 \%$ of patients with obesity have food disorders, among which the most common are hyperphagic stress response, compulsive hyperphagia, carbohydrate thirst and premenstrual hyperphagia. Hyperphagic reaction to stress, as a eating disorder is manifested by the fact that during psycho-emotional stress, anxiety, or immediately after the effect of the factor causing stress, the person suddenly increases appetite, and there is a desire to eat. In compulsive hyperphagia, patients periodically, for no reason, or for reasons they are not aware of, consume a large amount of food, often sweet and fatty. This type of disturbance includes night hyperphagia - an imperative increase in appetite in the evening and at night. To satisfy carbohydrate or food thirst, patients require both sugary and fatty foods (chocolate, ice cream, cream, etc.). In its absence, patients develop a depressive state, 
resembling abstinence. The mechanisms of the occurrence of food disorders are associated with a violation of serotonin transmission in brain structures responsible for the regulation of eating behavior [24]. At the same time, excessive fat intake can be formed as a family nutrition habit transmitted by education. Unfortunately, the number of obese families in recent times is becoming increasingly common.

As is known, the predisposition to the development of obesity is to reduce the ability to oxidize fat. One possible reason is the condition of the muscles and the composition of the muscle fibers. The bulk of body fat is oxidized in muscle tissue, in its slow and fast oxidative fibers, while fast glycolytic fibers in muscles are deprived of this ability. Obviously, with the predominance of this type of fibers in the muscles, the ability to oxidize lipids will be reduced [25].

The decrease in physical activity is the second most important after overeating environmental factor contributing to the development of obesity and IR. When hypodynamia occurs, lipolysis and utilization of triglycerides in muscle and adipose tissue slow down and translocation of glucose transporters in muscles decreases, which leads to the development of IR.

Genetic risk factors may also consist in the constitutional characteristics of the composition of muscle fibers, the distribution of fat, activity and insulin sensitivity of the main enzymes of carbohydrate and fat metabolism. The formation of MS is determined by a genetic predisposition to several groups of candidate genes [26]. One of these groups includes genes whose products determine elevated glucose levels. The number of candidate genes that can potentially influence the action of insulin is very large. Both in the signal chain of insulin action and in the processes of glucose uptake and metabolism, various proteins are involved, any change of which may affect insulin sensitivity [27].

Separately, it is necessary to single out a group of genes whose products regulate lipid metabolism and the development of obesity. At present, it is assumed that genes encoding apolipoprotein (a fatty acid carrier linked to cell membranes) can be associated with the development of MS [28].

The group of genes for which significant association with essential hypertension was found includes genes encoding angiotensinogen, the P-protein subunit and NO-synthetase of vascular endothelial cells [29].

The reasons for the widespread mutation of the mutations described above are not completely clear, but most researchers support the "economical genotype" theory put forward by Professor James Neel in 1962 [30]. According to this hypothesis, in the course of evolution, the most appropriate "thrift" genes were fixed in the genotype, providing IL with the aim of accumulating energy in the form of fat "in reserve". Under the primitive communal system, this process had an adaptive meaning for survival in conditions where the human nutritional capacity was irregular and the periods of abundance alternated with periods of prolonged starvation. However, for a very short - on the scale of evolution - a period of time in countries with a high standard of living, humanity switched to high-calorie nutrition combined with a decrease in the expenditure of muscle energy. The result of the mechanism of IR fixed in the genetic memory is the development of an MS pandemic, including its main components: obesity, dyslipidemia, arterial hypertension and type 2 diabetes.

Scientific studies have shown that excess adipose tissue, which has an auto-, para- and endocrine function is the basis for the development and progression of IR and is itself capable of secreting a large number of cytokines and vasoactive substances. To date, the most studied are leptin and adiponectin. Medications for chronic subacute inflammation also include TNF-alpha, C-reactive protein, interleukins (IL) 1, 6, and 8 [30].

Until now, the etiology and pathogenesis of MS are not fully disclosed. The publications containing the results of scientific studies describe various hormonal disorders that contribute to the development of abdominal obesity, including activation of the hypothalamic-pituitary-adrenal axis, an increase in testosterone and androstenedione, and a decrease in progesterone production in women, a decrease in testosterone and dihydrotestosterone in men, a decrease in growth hormone, increase in production of norepinephrine, contributing to the activation of the sympathetic nervous system [31].

Speaking about the pathogenetic mechanisms of MS development, it is impossible not to note the important role of endothelial dysfunction (ED). The term "endothelial dysfunction" refers to a decrease in the ability of endothelial cells to secrete relaxing factors while maintaining or increasing the level of production of vasoconstrictor factors, one of which is nitric oxide. Dysfunction of the vascular endothelium is one of the leading links in the development of atherosclerosis [32]. The final answer on the primary or secondary role of ED in the onset of $\mathrm{RI}$ is not currently received.

Thus, decoding the polygenic nature of inheritance, the study of the main etiological and pathogenetic mechanisms of MS is a priority scientific direction for scientists around the world. Summarizing the information presented, it can be concluded that metabolic syndrome has a widespread pathology that contains a set of pathogenetically interdependent disorders that are currently not studied in detail. Significant deviations from the norm of the main metabolic and hormonal parameters in obese people indicate a multiorgan 
lesion characteristic of this disease. This dictates the need for their more thorough monitoring with the study of all types of metabolism, including during exercise, as well as a more complete examination of the structure and function of all target organs.

\section{REFERENCES}

1. Uzokov, J., Alyavi, A., \& Alyavi, B. (2017). Prevalence and characteristics of metabolic syndrome in patients with bronchial asthma.

2. Kassi, E., Pervanidou, P., Kaltsas, G., \& Chrousos, G. (2011). Metabolic syndrome: definitions and controversies. BMC medicine, 9(1), 48.

3. Uzokov, J. K., Alyavi, A. L., Akhmedov, I. Y., Karimov, B. B., \& Rakhmonkulov, E. J. (2016). Efficacy and safety of combined antihypertensive therapy with ramipril and moxonidine in patients with metabolic syndrome. Journal of the American Society of Hypertension, 10(4), e54.

4. Alyavi, A., \& Uzokov, J. (2016). Depressive impairments in patients with metabolic syndrome. In clinical cardiology . 111 RIVER ST, HOBOKEN 07030-5774, NJ USA: WILEY-BLACKWELL. 39:14-14.

5. Сайдалиев, Р. С., Маматкулов, Х. А., Усаров, М. Х., \& Узоков, Ж. К. (2015). ३-АДРЕНОБЛОКАТОРЫ И ОСТРЫЙ ИНФАРКТ МИОКАРДА. Вестник экстренной медицины, (2).

6. Chen, G. C., Szeto, I. M., Chen, L. H., Han, S. F., Li, Y. J., Van Hekezen, R., \& Qin, L. Q. (2015). Dairy products consumption and metabolic syndrome in adults: systematic review and meta-analysis of observational studies. Scientific reports, 5, 14606.

7. A.Alyavi, J.Uzokov.(2016). Metabolic syndrome // Tashkent: 1-129.

8. Te Morenga, L. A., Howatson, A. J., Jones, R. M., \& Mann, J. (2014). Dietary sugars and cardiometabolic risk: systematic review and meta-analyses of randomized controlled trials of the effects on blood pressure and lipids. The American journal of clinical nutrition, 100(1), 65-79.

9. Park, J. B. (2016). The Pulse of Asia 2016 Seoul, September 24-26, 2016, Seoul, Republic of Korea: Abstracts. Pulse, 4(2-3), 93.

10. Аляви Б.А, Узоков Ж.К. (2017). Метаболик синдром ва артериал гипертензия // Тошкент : Niso-Poligraf, 144 б. уЎК 616.12008.331 .1$.

11. Guo, X. F., Li, X., Shi, M., \& Li, D. (2017). n-3 polyunsaturated fatty acids and metabolic syndrome risk: a metaanalysis. Nutrients, 9(7), 703.

12. Lutfullayevich, A. A., Anisxonovich, A. B., Kamilovich, U. J., Ismatovich, A. S., \& Ulugbekovich, K. N. (2017). GW28-e0699 Cardiovascular risk stratification and gender differences in hypertensive patients with metabolic syndrome. Journal of the American College of Cardiology, 70(16 Supplement), C138-C139.

13. Alyavi, B., Uzokov, J., \& Kamilova, S. (2018, May). Influence of telmisartan and amlodipine combination on blood pressure, echocardiographic parameters and microalbuminuria in patients with metabolic syndrome. In nephrology dialysis transplantation. Great clarendon st, oxford ox2 6dp, england: oxford univ press.33:374.

14. Ahmedov, I., Mirzaev, T., Uzokov, J., \& Jurakulov, N. (2016). Features of hyperreninemic aldosteronism in hypertension patients with metabolic syndrome: 87. European Journal of Preventive Cardiology, 23(1).

15. Reaven, G. M. (1988). Role of insulin resistance in human disease. Diabetes, 37(12), 1595-1607.

16. Uzokov, J., Alyavi, A., \& Karimov, B. (2016). Prevalence of metabolic syndrome in patients with chronic obstructive pulmonary disease.

17. Borkman, M., Campbell, L. V., Chisholm, D. J., \& Storlien, L. H. (1991). Comparison of the effects on insulin sensitivity of high carbohydrate and high fat diets in normal subjects. The Journal of Clinical Endocrinology \& Metabolism, 72(2), $432-437$.

18. Uzokov, J. J., \& Alyavi, A. (2015). Comparison of enalapril-amlodipine and captopril-indapamide combinations in the management of hypertension patients with metabolic syndrome: P392. European Journal of Heart Failure, 17.

19. Usarov, M., Mamatkulov, X., Uzokov, J., Hojiev, S., Yakhshilikov, D., \& Dadaev, S. (2016). Ps 11-56 Efficacy Of Combination Therapy Using Nebivalol And Trimetazidine In Hypertensive Patients With Metabolic Syndrome And Stable Angina. Journal of Hypertension, 34, e349.

20. Spahis, S., Borys, J. M., \& Levy, E. (2017). Metabolic syndrome as a multifaceted risk factor for oxidative stress. Antioxidants \& redox signaling, 26(9), 445-461.

21. Lutfullayevich, A. A., Anisxonovich, A. B., Kamilovich, U. J., Ismatovich, A. S., \& Ulugbekovich, K. N. (2017). GW28-e0698 Telmisartan with amlodipine versus lisinopril with amlodipine on home blood pressure variability in patients with metabolic syndrome. Journal of the American College of Cardiology, 70(16 Supplement), C138.

22. Palmieri, V. O., Grattagliano, I., Portincasa, P., \& Palasciano, G. (2006). Systemic oxidative alterations are associated with visceral adiposity and liver steatosis in patients with metabolic syndrome. The Journal of nutrition, 136(12), 3022-3026.

23. Alyavi, B., Uzokov, J., \& Payziev, D. (2018). TCTAP A-081 Influence of Low Glycemic Diet on Lipid Profile in Patients with Ischemic Disease of the Heart After Percutaneous Intervention. Journal of the American College of Cardiology, 71(16 Supplement), S45.

24. Zelzer, S., Fuchs, N., Almer, G., Raggam, R. B., Prüller, F., Truschnig-Wilders, M., ... \& Ille, R. (2011). High density lipoprotein cholesterol level is a robust predictor of lipid peroxidation irrespective of gender, age, obesity, and inflammatory or metabolic biomarkers. Clinica chimica acta, 412(15-16), 1345-1349.

25. Mukhamedova, M., Alyavi, B. A., Uzokov, J. K., Babaev, M. A., \& Kamilova, S. E. (2019). P120 Relationship between left ventricular global function index and cardiac systolic functions in patients with chronic ischemic disease of the heart and diabetes mellitus. European Heart Journal-Cardiovascular Imaging, 20(Supplement_3), jez147-008. 
26. Абдуллаев, А. Х., Аляви, Б. А., Раимкулова, Н. Р., Узоков, Ж. К., Азизов, Ш. И., Каримова, Д. К., ... \& Иминова, Д. А. (2019). ОЦЕНКА ЭФФЕКТИВНОСТИ КОЛМСТРЕС У БОЛЬНЫХ КОРОНАРНОЙ БОЛЕЗНЬЮ СЕРДЦА. КардиоваскУЛярная терапия и профилактика, 18(S1), 5-6.

27. Vitali, C., Khetarpal, S. A., \& Rader, D. J. (2017). HDL cholesterol metabolism and the risk of CHD: new insights from human genetics. Current cardiology reports, 19(12), 132.

28. Yubero-Serrano, E. M., Delgado-Lista, J., Tierney, A. C., Perez-Martinez, P., Garcia-Rios, A., Alcala-Diaz, J. F., ... \& Blaak, E. E. (2015). Insulin resistance determines a differential response to changes in dietary fat modification on metabolic syndrome risk factors: the LIPGENE study. The American journal of clinical nutrition, 102(6), 1509-1517.

29. Uzokov, J. K., Alyavi, B. A., \& Abdullaev, A. X. (2019, May). Combined therapy with rosuvastatin and ezetimibe on inflammatory state and pro-inflammatory cytokines in patients with coronary heart disease and metabolic syndrome. In european journal of heart failure. 111 RIVER ST, hoboken 07030-5774, NJ USA: WILEY,21:133-133.

30. Uzokov, J., Alyavi, A., \& Alyavi, B. (2017). Influence of combination therapy of rosuvastatin and telmisartan on vascular and metabolic profile in hypercholesterolemic patients with metabolic syndrome. Atherosclerosis, 263 , e241.

31. AL, A., Alyavi, B. A., Tulyaganova, D. K., Aliahunova, M. Y., Sabirzhanova, Z. T., Nuritdinova, S. K., ... \& Sayfiev, N. Y. (2018). Features of Inflammatory Markers in Patients With Coronary Heart Disease. International Journal of Healthcare and Medical Sciences, 4(10), 188-192.

32. Babaev, M., Alyavi, A. L., Alyavi, B. A., \& Uzokov, J. K. (2018). P2533 Influence of l-arginine aspartate on vascular markers in hypertensive patients with metabolic syndrome. European Heart Journal, 39(suppl_1), ehy565-P2533. 